\title{
Transcutaneous electrical acupoint stimulation for prevention of postoperative delirium in geriatric patients with silent lacunar infarction: a preliminary study
}

This article was published in the following Dove Press journal: Clinical Interventions in Aging

\author{
Fang Gao' \\ Qi Zhang² \\ Yanan $\mathrm{Li}^{\prime}$ \\ Yanlei Tai ${ }^{\prime}$ \\ Xi Xin ${ }^{3}$ \\ Xiuli Wang' \\ Qiujun Wang' \\ 'Department of Anesthesiology, \\ The Third Hospital of Hebei Medical \\ University, Shijiazhuang City, \\ Hebei, People's Republic of China; \\ ${ }^{2}$ Department of Anesthesiology, \\ Children's Hospital of Hebei Province, \\ Shijiazhuang City, Hebei, People's \\ Republic of China; ${ }^{3}$ Department of \\ Anesthesiology, Tianjin Third Central \\ Hospital, Tianjin, People's Republic \\ of China
}

Correspondence: Qiujun Wang

Department of Anesthesiology, The Third Hospital of Hebei Medical University,

No 139, Ziqiang Road, Shijiazhuang City,

Hebei, People's Republic of China

Tel/fax +86 3II 88602072

Email1393317800।@I63.com
Purpose: This study aims to investigate the effect of transcutaneous electrical acupoint stimulation (TEAS) on postoperative delirium (POD) in elderly patients with silent lacunar infarct and preliminarily to determine the relationship among TEAS, blood-brain barrier (BBB), neuroinflammation, and POD.

Patients and methods: Sixty-four-old patients with silent lacunar infarct were randomly divided into two groups: group TEAS and control group (group C). Patients in the group TEAS received TEAS (disperse-dense waves; frequency, 2/100 Hz) on acupoints Hegu and Neiguan of both sides starting from 30 minutes before induction of anesthesia until the end of surgery, and the intensity was the maximum current that could be tolerated. In group $\mathrm{C}$, electrodes were placed on the same acupoints before anesthesia induction, but no current was given. At 0 minute before the treatment of TEAS, 30 minutes after skin incision, and after completion of surgery $\left(\mathrm{T}_{1-3}\right)$, blood samples were extracted to detect the concentration of serum tumor necrosis factor (TNF)- $\alpha$, interleukin-6 (IL-6), matrix metalloproteinase-9 (MMP-9), and S100 $\beta$. We assessed patients for delirium and coma twice daily in the first 3 postoperative days using the Confusion Assessment Method for the intensive care unit and the Richmond Agitation-Sedation Scale.

Results: This study preliminarily suggests that TEAS can reduce the development of POD in elderly patients with silent lacunar infarction $(6.3 \%$ vs $25.0 \% ; P=0.039)$. Compared with the baseline value at $T_{1}$, the serum concentrations of IL-6, TNF- $\alpha$, MMP-9, and S100 $\beta$ were significantly increased at $\mathrm{T}_{2-3}$ in both the groups $(P<0.05)$. Compared with group TEAS, serum levels of TNF- $\alpha$ and IL-6 were higher at $\mathrm{T}_{2-3}$ and serum levels of MMP-9 and S100 $\beta$ were higher at $\mathrm{T}_{3}$ in group $\mathrm{C}(P<0.05)$. The intraoperative anesthetic consumptions were less in group TEAS than group $\mathrm{C}$.

Conclusion: TEAS can alleviate POD in older patients with silent lacunar infarction and may be related to reduce the neuroinflammation by lowering the permeability of BBB.

Keywords: delirium, geriatric, neuroinflammation, blood-brain barrier, transcutaneous electrical acupoint stimulation, lacunar infarction

\section{Introduction}

Postoperative delirium (POD) is a common complication of surgical procedures in the elderly and causes difficulty in postoperative care. Acute and fluctuating alterations of consciousness, attention, and cognition are characteristic features of delirium. ${ }^{1}$ It is associated with increased length of stay, increased charges, decreased odds of discharge to home, and accelerated cognitive decline. ${ }^{2,3}$ The multifactorial reason and 
obscure pathogenesis of delirium have made it challenging to prevent and treat. So far, although various approaches (such as nimodipine) aimed at alleviating the incidence of POD have shown early promise in efficacy trials, ${ }^{4-6}$ there are no conclusive studies that support nonpharmaceutic technique to prevent or decrease POD.

The blood-brain barrier (BBB) is a multicellular vascular structure that separates the central nervous system (CNS) from the peripheral blood circulation. The main functions of this barrier, namely maintenance of brain homeostasis, regulation of influx and efflux transport, and protection from harm, are determined by its specialized multicellular structure. Endothelial cells (ECs), astrocytes, pericytes, and extracellular matrix (ECM) components provide both structural and functional supports to the BBB. Every constituent cell type makes an indispensible contribution to the BBB's integrity. But, if one member of the BBB fails and, as a result, the barrier breaks down, there can be dramatic consequences, and neuroinflammation and neurodegeneration can occur. ${ }^{7}$

Impairment of the BBB occurs as people age and may account for the greater susceptibility to stroke. ${ }^{8}$ Lacunar infarcts accounts for up to $25 \%$ of stroke. ${ }^{9}$ Involving small penetrating cerebral arteries, lacunes are usually attributed to cerebral microatheromatosis and lipohyalinosis, although the absence of pathological evidence of occluded vessels has raised doubts about this theory. ${ }^{10,11}$ Lacunar infarcts are often clinically silent, but these silent subclinical events contribute significantly to the risk of large vessel stroke, ${ }^{12,13}$ disability, ${ }^{14}$ vascular dementia, ${ }^{15}$ and death. ${ }^{16}$ Wardlaw et $a{ }^{10}$ found that lacunar stroke is associated with a generalized increase in BBB leakiness.

Acupuncture, an important component of traditional Chinese medicine, has been used for more than 2,000 years to treat diseases and relieve pain. ${ }^{17}$ Transcutaneous electric acupoint stimulation (TEAS), or "needleless acupuncture", is an easy and noninvasive alternative to needle-based electroacupuncture (EA). It combines the advantages of both acupuncture and transcutaneous electrical nerve stimulation by pasting electrode pads on the acupoints instead of piercing the skin with needles. TEAS makes it possible to achieve better outcomes with fewer anesthetic drugs. ${ }^{18}$ Studies showed that acupuncture exerts protective effect on the brain through maintaining the BBB integrity, ${ }^{19}$ but its effect on alleviating POD remains to be discussed.

This research aims to investigate the effect of TEAS on POD in geriatric adults with silent lacunar infarct and preliminarily to determine the relationship among TEAS, $\mathrm{BBB}$, neuroinflammation, and POD. Results may provide reference for clinical applications. We tested the hypothesis that TEAS could reduce POD and could be associated with alleviation of neuroinflammation by lowering the permeability of BBB.

\section{Patients and methods Patients and setting}

The present study has been performed with the approval of the ethics committee of the Third Hospital of Hebei Medical University (2016-012-1) and is in compliance with the Helsinki Declaration. Written informed consents of the study were collected from all the candidate subjects before randomization. The inclusion criterion was patients aged 65 years or older who underwent spine surgery in the Third Hospital of Hebei Medical University in July 2017. All patients were assessed for lacunar infarction by magnetic resonance imaging. The basic patient information was collected, including age, sex, body mass index (BMI), and American Society of Anesthesiologists' physical status I or II. The mini-mental state examination (MMSE) was administered to screen for preoperative cognitive function 1 day before the surgery. Patients were excluded if they met any of the following criteria: MMSE score of less than 24 or dementia, due to various etiologies, preoperative delirium, history of neurological or mental illness, current use of tranquilizers or antidepressants, history of an endocrine or metabolic disorder, recent use of glucocorticoids or other hormones, suffering from infections or chronic inflammatory conditions, intake of anti-inflammatory drugs, unwillingness to complete the experimental procedures, inability to communicate in the preoperative period (language barrier or severe hearing or visual impairment), and alcohol or drug dependence. Six patients were excluded because of these criteria. As shown in Figure 1, only 64 patients were enrolled in the study. The patients were divided into two groups $(n=32)$ by using a random number table: transcutaneous electrical acupoint stimulation group (group TEAS) and control group (group C).

\section{Anesthesia management}

After entering the operating room, electrocardiogram, pulse oxygen saturation, respiratory rate, end-tidal carbon dioxide, bispectral index (BIS), and invasive blood pressure were continuously recorded in the both groups during the perioperative period. All patients received ultrasound-guided retrograde puncture of internal jugular vein, then $12-14 \mathrm{~cm}$ of catheter was inserted into the deep vein catheter to jugular bulb using Seldinger method, and the location of the catheter was confirmed by X-ray. 


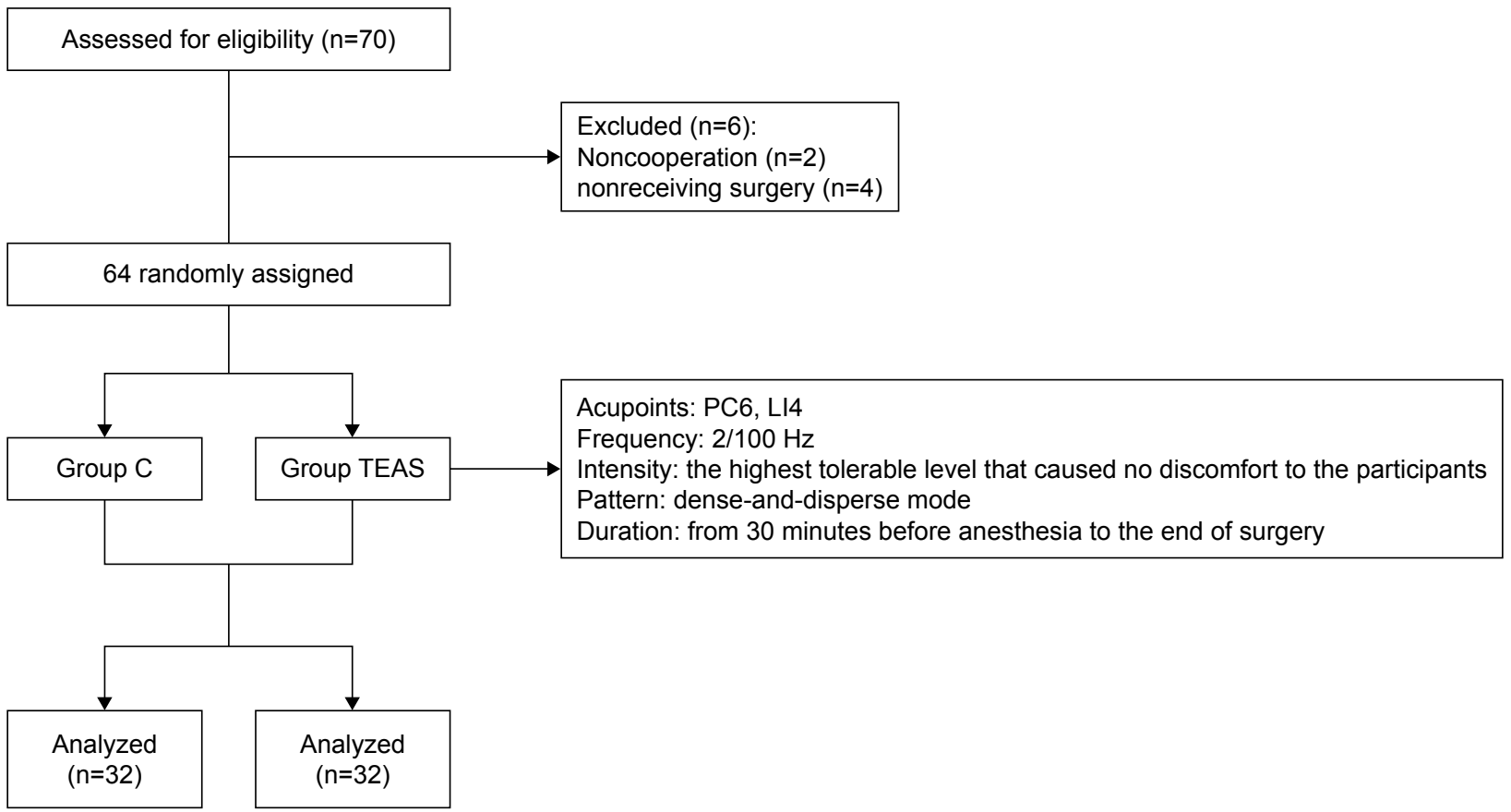

Figure I Experimental flow of this study.

Abbreviations: C, control; LI4, Hegu acupoint; PC6, Neiguan acupoint; TEAS, transcutaneous electrical acupoint stimulation.

\section{Anesthesia induction}

The patients were induced using $0.1-2 \mu \mathrm{g} / \mathrm{kg}$ sufentanil, $0.05-0.2 \mathrm{mg} / \mathrm{kg}$ midazolam, $0.3 \mathrm{mg} / \mathrm{kg}$ etomidate, and $0.2 \mathrm{mg} / \mathrm{kg}$ cisatracurium. A reinforced catheter was inserted after 2 minutes of cisatracurium administration. Ventilation frequency was set to 12 times per minute, inspiratory expiratory ratio to $1.0: 1.5$, inhaled oxygen concentration to $100 \%$, oxygen flow to $2 \mathrm{~L} / \mathrm{min}$, and $\mathrm{ETCO}_{2}$ was maintained within the physiologic limits (35-45 $\mathrm{mmHg}$ ).

\section{Anesthesia maintenance}

According to the theory of traditional Chinese medicine, as shown in Figure 2, bilateral Hegu (LI4, located at the back of the hand, between the first and second metacarpal bones, at the midpoint of the second metacarpal radius) and Neiguan (PC6, located in the palmar of the forearm, 2 inches in the wrists) were chosen as the acupuncture points. In group TEAS, the patients received TEAS (disperse-dense waves; frequency, $2 / 100 \mathrm{~Hz}$ ) on acupoints LI4 and PC6 on both sides starting from 30 minutes before induction of anesthesia until the end of the surgery, and the intensity was the maximum current that could be tolerated. In group C, electrodes were placed on the same acupoints before anesthesia induction, but no current was given. Propofol 4-6 mg/kg/h and remifentanil $0.1-0.3 \mu \mathrm{g} / \mathrm{kg} / \mathrm{min}$ were intravenously (iv) infused and cisatracurium $0.05 \mathrm{mg} / \mathrm{kg}$ was administrated as intermittent iv boluses.
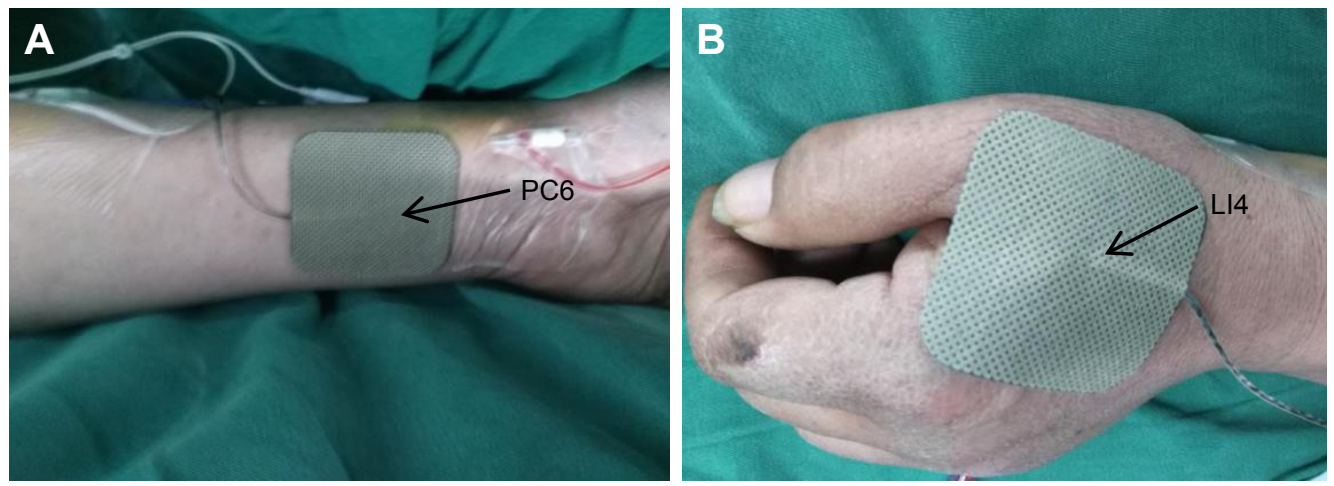

Figure 2 The location of the electrodes used for transcutaneous electrical acupoint stimulation.

Notes: (A) PC6, located in the palmar of the forearm, 2 inches in the wrists. (B) LI4, located at the back of the hand, between the first and second metacarpal bones, at the midpoint of the second metacarpal radius.

Abbreviations: LI4, Hegu acupoint; PC6, Neiguan acupoint. 
Intraoperative circulatory system was maintained by adjusting the anesthesia depth (controlling BIS, 40-60) and administering transfusions or cardiovascular agents as necessary. Blood pressure fluctuation amplitude did not exceed $20 \%$ of the base value. Atropine was used only to reverse bradycardia. After the surgery, tracheal intubation was removed when patients regained consciousness, tidal volume was $8 \mathrm{~mL} / \mathrm{kg}$, and all hemodynamic parameters such as heart rate and blood pressure returned to the normal level.

\section{Pain control}

Sufentanil $(0.15 \mu \mathrm{g} / \mathrm{kg})$ and tropisetron $(5 \mathrm{mg})$ were administered 10 minutes before the end of the surgery for analgesia transition and prevention of postoperative nausea and vomiting (PONV). A patient-controlled iv analgesia pump was connected $(1.5 \mu \mathrm{g} / \mathrm{kg}$ sufentanil and $6 \mathrm{mg}$ tropisetron; flow rate, $2 \mathrm{~mL} / \mathrm{h}$; bolus, $0.5 \mathrm{~mL}$; lockout time, 15 minutes). Postoperative pain was assessed using VAS ${ }^{20}$ in 24 hours after surgery. If the VAS score was greater than or equal to 4 or patients required analgesics within 24 hours, the patient received $50 \mathrm{mg}$ flurbiprofen as rescue analgesia.

\section{Blood sample collection and sample bank establishment}

At 0 minute before the treatment of TEAS $\left(\mathrm{T}_{1}\right), 30$ minutes after skin incision $\left(\mathrm{T}_{2}\right)$, and after completion of surgery $\left(\mathrm{T}_{3}\right)$, $4 \mathrm{~mL}$ blood samples were taken from the jugular bulb. Blood samples were immediately placed into sterile EDTA test tubes and centrifuged at $3,000 \times g$ for 15 minutes to collect serum. Serum was aliquoted into polypropylene tubes and stored in a freezer at $-80^{\circ} \mathrm{C}$ (Sanyo, Japan) until further assayed.

\section{Cytokine measurement}

The concentrations of tumor necrosis factor (TNF)- $\alpha$, interleukin-6 (IL-6), matrix metalloproteinase-9 (MMP-9), and $\mathrm{S} 100 \beta$ in serum were quantified with a commercial ELISA kit (ExCell Biotech [Taicang] Co., Shanghai, People's Republic of China) in accordance with the manufacturer's instructions. The trained research personnel carrying out the assays was blinded to the group assignment.

\section{Delirium evaluation}

After enrollment, trained research personnel who were blinded to group assignment assessed patients' results for POD and coma using the Confusion Assessment Method for the intensive care unit (CAM-ICU) $)^{21,22}$ and the Richmond Agitation-Sedation Scale (RASS) ${ }^{23,24}$ twice daily from the first to third postoperative day in the morning and in the afternoon or evening, with at least 6 hours elapsing between assessments. Patients were also assessed on the day of surgery at least 2 hours after the end of the surgery. We considered a patient delirious if they were not comatose (ie, had an RASS of -3 or more awake) and were CAM-ICU positive on either of the CAM-ICU assessments. Patients with an RASS of -4 (responsive to physical stimulus only) or -5 (completely unresponsive) were considered comatose.

\section{Other outcomes}

The primary outcomes were the incidence of POD. Secondary outcome included intraoperative propofol and remifentanil consumption.

\section{Statistical analyses}

All data were analyzed by SPSS (version 22.0 for Windows; IBM Corporation, Armonk, NY, USA). Measurement data of normal distribution were reported as the mean \pm SD. Categorical variables were analyzed through chi-squared test or the Fisher's exact probability test (when appropriate) and presented as numbers (\%). Comparisons between two groups were performed with Student's $t$-test. Repeated measurements were compared using repeated measure' ANOVA. For all tests, $P<0.05$ was considered statistically significant.

\section{Results \\ Clinical characteristics of patients and operation/anesthesia duration}

All the patients received $100 \mathrm{mg}$ aspirin once daily for preventing lacunar infarction. As shown in Table 1, there were no significant differences in clinical characteristics between the two groups, including gender, age, BMI, American Society of Anesthesiologists (ASA), operation duration, and anesthesia duration $(P>0.05)$.

\section{IL-6, TNF- $\alpha$, SI 00ß, and MMP-9 Levels}

As shown in Table 2, compared with the baseline value at $\mathrm{T}_{1}$, the serum concentrations of IL-6, TNF- $\alpha$, MMP-9, and $\mathrm{S} 100 \beta$ were significantly increased at $\mathrm{T}_{2-3}(P<0.05)$. Compared with group TEAS, serum levels of TNF- $\alpha$ and IL-6 were higher at $\mathrm{T}_{2-3}$ and serum levels of MMP-9 and $\mathrm{S} 100 \beta$ were higher at $\mathrm{T}_{3}$ in group $\mathrm{C}(P<0.05)$.

\section{The prevalence of POD, intraoperative propofol, and remifentanil consumption}

As shown in Table 3, the prevalence of POD was statistically significantly lower in group TEAS than in group $\mathrm{C}$ $(P<0.05)$. Compared with group $\mathrm{C}$, intraoperative propofol 
Table I Clinical characteristics of patients and operation/ anesthesia duration $(n=32)$

\begin{tabular}{|c|c|c|c|}
\hline Characteristics & TEAS & C & $P$-value* \\
\hline Age (years) & $7 I \pm 5$ & $73 \pm 4$ & 0.058 \\
\hline Gender (male/female), $\mathrm{n}$ & $15 / 17$ & $18 / 14$ & 0.453 \\
\hline BMI $\left(\mathrm{kg} / \mathrm{m}^{2}\right)$ & $26.6 \pm 2.5$ & $26.5 \pm 2.2$ & 0.864 \\
\hline ASA (physical status I/II), $n$ & $19 / 13$ & $17 / 15$ & 0.614 \\
\hline Operation duration (minutes) & $136 \pm 8$ & $134 \pm 9$ & 0.735 \\
\hline Anesthesia duration (minutes) & $|7| \pm 8$ & $167 \pm 11$ & 0.053 \\
\hline Infarct topography & & & 0.777 \\
\hline Basal ganglia $(n)$ & 26 & 28 & \\
\hline Corona radiata $(n)$ & 2 & 1 & \\
\hline Thalamus (n) & 4 & 3 & \\
\hline
\end{tabular}

Notes: Data are expressed as mean \pm SD. Independent sample $t$-test was used to compare age, operation duration, anesthesia duration, and BMI between groups. Chi-squared test was used to compare gender and ASA physical status between groups. The significance level was set at $P<0.05$. $* P$-value for the comparison of outcome variables between groups.

Abbreviations: ASA, American Society of Anesthesiologists; BMI, body mass index; C, control; TEAS, transcutaneous electrical acupoint stimulation.

and remifentanil consumptions were significantly decreased in the TEAS group $(P<0.05)$.

\section{Discussion}

In this study, we preliminary found that TEAS can reduce the development of POD in geriatric patients with silent lacunar infarction undergoing spine surgery. The underlying mechanism may be related to the inhibition of neuroinflammation by lowering the permeability of BBB, which is consistent with our hypothesis.

Intraoperative anesthetic use was linked to significantly higher odds of delirium. ${ }^{25}$ Perioperative opioids have been linked to sleep disturbances, which may negatively impact

Table 2 Serum IL-6, TNF- $\alpha$, MMP-9, and SI00 levels ( $n=32)$

\begin{tabular}{|c|c|c|c|c|}
\hline & Group & $\mathbf{T}_{\mathbf{1}}$ & $\mathbf{T}_{2}$ & $\mathbf{T}_{3}$ \\
\hline \multirow[t]{2}{*}{ IL-6 $(\mu \mathrm{g} / \mathrm{mL})$} & C & $35.9 \pm 2.7$ & $56.7 \pm 6.5^{*}$ & $62.1 \pm 6.7^{*}$ \\
\hline & TEAS & $35.4 \pm 2.9$ & $52.4 \pm 6.6^{* \# \#}$ & $58.8 \pm 6.1^{* \# \#}$ \\
\hline \multirow[t]{2}{*}{ TNF- $\alpha(\mu \mathrm{g} / \mathrm{mL})$} & C & $19.7 \pm 0.8$ & $30.4 \pm 5.6^{*}$ & $38.4 \pm 7.1^{*}$ \\
\hline & TEAS & $19.9 \pm 0.9$ & $26.7 \pm 5.7^{* \# \#}$ & $33.4 \pm 6.3^{* \#}$ \\
\hline \multirow[t]{2}{*}{ MMP-9 (ng/mL) } & C & $3.2 \pm 0.5$ & $3.5 \pm 0.5^{*}$ & $4.1 \pm 0.6 *$ \\
\hline & TEAS & $3.0 \pm 0.6$ & $3.3 \pm 0.7 *$ & $3.7 \pm 0.7 *, \#$ \\
\hline \multirow[t]{2}{*}{$\mathrm{SI} 00 \beta(\mathrm{pg} / \mathrm{mL})$} & C & $51.5 \pm 6.3$ & $60.8 \pm 7.5^{*}$ & $90.2 \pm 13.1^{*}$ \\
\hline & TEAS & $52.8 \pm 8.9$ & $59.9 \pm 10.2^{*}$ & $83.2 \pm 12.5^{* \#}$ \\
\hline
\end{tabular}

Notes: Data are expressed as mean \pm SD. Comparisons between two groups were performed using Student's $t$-test. Repeated measurements were compared using repeated measure ANOVA. $* P<0.05$ vs $T_{1} ;{ }^{*} P<0.05$ vs the group $C$. $T_{1}$ : at 0 minute before the treatment of TEAS; $T_{2}: 30$ minutes after skin incision; and $T_{3}$ : after completion of surgery. Abbreviations: C, control; IL-6, interleukin-6; MMP-9, matrix metalloproteinase-9; TEAS, transcutaneous electrical acupoint stimulation; TNF- $\alpha$, tumor necrosis factor- $\alpha$.
Table 3 The prevalence of postoperative delirium, intraoperative propofol, and remifentanil consumption $(n=32)$

\begin{tabular}{|l|l|l|l|}
\hline Group & TEAS & C & P-value* \\
\hline Prevalence of delirium, n (\%) & $2(6.3)^{*}$ & $8(25.0)$ & 0.039 \\
\hline Propofol $(\mathrm{mg})$ & $469 \pm 33^{*}$ & $498 \pm 3 \mathrm{I}$ & $0.00 \mathrm{I}$ \\
\hline Remifentanil $(\mu \mathrm{g})$ & $545 \pm 35^{*}$ & $636 \pm 33$ & $<0.00 \mathrm{I}$ \\
\hline
\end{tabular}

Notes: Data are expressed as mean \pm SD or $n(\%)$. Independent sample $t$-test was used to compare propofol and remifentanil between groups. Chi-squared test was used to compare prevalence of delirium between groups. The significance level was set at $P<0.05$. *P-value for the comparison of outcome variables between groups. Abbreviations: C, control; TEAS, transcutaneous electrical acupoint stimulation.

cognitive function. ${ }^{26}$ In one review of opioid usage among chronic pain patients, the cognitive side effects from opioids were most apparent within several hours of an initial dose, ${ }^{27}$ which could explain the increased risk for POD among patients who received opioids intraoperatively. The anesthetic propofol can also directly increase tau protein phosphorylation, ${ }^{28}$ which is associated with the development of neurofibrillary pathology. Another mechanism is that anesthetics weaken BBB, and then surgery-induced inflammation may cross the damaged BBB and directly injure neurons, causing elevated biomarkers of neuronal injury and perhaps some of the long-term adverse effects of delirium. ${ }^{29}$ Several studies indicated that TEAS could reduce the narcotics consumption. ${ }^{30-32}$ In the present study, TEAS decreased the anesthetics consumption during operation compared with those in group C. It is consistent with the previous studies.

Markers of neurologic injury, which are released into the blood when neurons or the $\mathrm{BBB}$ is damaged, provide a more feasible measure of BBB injury. Of the markers previously studied, $\mathrm{S} 100 \beta$ is the one that mostly correlated with BBB injury. ${ }^{33-35} \mathrm{~S} 100 \beta$ is expressed and secreted by astrocytes after CNS injury or ischemia and cell death. ${ }^{36}$ MMPs are proteolytic enzymes that degrade all components of the ECM. ${ }^{37}$ MMP-9 is one of the inducible MMPs, which are held in an inactive state until a neuroinflammatory process begins and they become active through the action of free radicals and other enzymes. Once the inducible MMPs are activated, they degrade the basal lamina and tight junctions of ECs, thereby opening the BBB. ${ }^{38}$ By using ELISA, we found the significantly lower level of S100 $\beta$ and MMP-9 in patients of the group TEAS than those of the group C. These results indicate that TEAS can reduce the occurrence of POD, which may be related to alleviate the damage of BBB.

CNS-resident cells react to the peripheral immune signal and produce cytokines and other inflammatory mediators in the brain due to the altered permeability of the BBB..$^{39,40}$ The amount of production of TNF- $\alpha$ and IL- 6 is considered 
as the main cause of the cognitive impairment in POD, and this process may be accelerated in the elderly. ${ }^{41-44}$ TNF- $\alpha$ can stimulate the expression of other mediators responsible for the recruitment of additional inflammatory cells. ${ }^{45,46}$ Studies evidence that TNF- $\alpha$ is also in the communication between the periphery tissue and the brain. ${ }^{47-49}$ The high level of IL- 6 is considered to be an indicator of delirium. The relationship between increased IL-6 and neuronal damage has been proposed in some studies. ${ }^{50-52}$ In the present study, significant difference of serum TNF- $\alpha$ and IL- 6 levels existed between group TEAS and group $C$, suggesting that TEAS could significantly reduce neuroinflammation.

The location of lacunar infarcts in the thalamus and the basal ganglia is more likely to show cognitive impairment. ${ }^{53-55}$ The number of silent lacunar infarction was associated with mild neuropsychological abnormalities. ${ }^{56}$ In our study, the lacunar infarcts were mainly in the basal ganglia, and all the patients suffered from multiple silent lacunar infarctions. We tested MMSE with patients before the surgery to rule out confounding factors. In future studies, it will be useful to take into consideration the region and the number of silent lacunar infarction, whose impact on POD has not been recognized.

The current research exhibits certain limitations. Patients with POD had an increased risk of dementia at follow-up. ${ }^{57-59}$ In the current study, the observation time is short. Prolonging the observation time might be helpful in guiding the management of delirious patients and assessing whether POD disturbances are a predictive factor of vascular dementia in the mid-term. In our patient population, there were only two patients with the age of $\geq 85$ years, but it should be proposed as an interesting area of research to analyze the effect of TEAS on very elderly patients who have a worse prognosis compared to the rest of lacunar infarcts. ${ }^{60}$ As acupuncture and related technique are traditional practices in Chinese culture, the psychological effect of higher acceptance might create a higher satisfactory result than in other ethic population. Moreover, this is a single-center study in a strictly defined patient population, which may be interpreted with care. A prospective randomized, double-blind, multicenter trial is justified.

\section{Conclusion}

TEAS exerts beneficial effect on POD in geriatric population with silent lacunar infarction, and such effect may be related to reduce neuroinflammation by lowering the permeability of BBB. However, the favorable effects of TEAS on improving long-term treatment outcomes remain unknown. Further work should be conducted to elucidate the mechanisms by which TEAS can intervene the development of delirium.

\section{Acknowledgments}

We would like to thank Meng Zhao, Chunping Yin, and Yangyang Guo for their advice and support on the design and analysis of this project. This work was supported by the National Natural Science Foundation of China (81771134), Natural Science Foundation of Hebei Province(H2018206305), and Hebei Provincial Government Funded Clinical Talents Cultivation and Basic Research Projects (361005).

\section{Disclosure}

The authors report no conflicts of interest in this work.

\section{References}

1. Inouye SK, Westendorp RG, Saczynski JS. Delirium in elderly people. Lancet. 2014;383(9920):911-922.

2. Brown CH, Laflam A, Max L, et al. Delirium after spine surgery in older adults: incidence, risk factors, and outcomes. $J$ Am Geriatr Soc. 2016;64(10):2101-2108.

3. Davis DH, Muniz-Terrera G, Keage HA, et al. Association of delirium with cognitive decline in late life: a neuropathologic study of 3 population-based cohort studies. JAMA Psychiatry. 2017;74(3):244-251.

4. Chan MT, Cheng BC, Lee TM, Gin T, CODA Trial Group. BIS-guided anesthesia decreases postoperative delirium and cognitive decline. J Neurosurg Anesthesiol. 2013;25(1):33-42.

5. Hudetz JA, Patterson KM, Iqbal Z, et al. Ketamine attenuates delirium after cardiac surgery with cardiopulmonary bypass. J Cardiothorac Vasc Anesth. 2009;23(5):651-657.

6. Yn L, Zhang Q, Wang QJ. Effect of nimodipine on postoperative delirium in elderly patients with lacunar infarction. Chin J Anesthesiol. 2018;38(3):262-265.

7. Obermeier B, Daneman R, Ransohoff RM. Development, maintenance and disruption of the blood-brain barrier. Nat Med. 2013;19(12):1584-1596.

8. Zeevi N, Pachter J, Mccullough LD, Wolfson L, Kuchel GA. The bloodbrain barrier: geriatric relevance of a critical brain-body interface. $J \mathrm{Am}$ Geriatr Soc. 2010;58(9):1749-1757.

9. Hinman JD, Lee MD, Tung S, Vinters HV, Carmichael ST. Molecular disorganization of axons adjacent to human lacunar infarcts. Brain. 2015; 138(Pt 3):736-745.

10. Wardlaw JM, Doubal F, Armitage P, et al. Lacunar stroke is associated with diffuse blood-brain barrier dysfunction. Ann Neurol. 2009;65(2): 194-202.

11. Arboix A, López-Grau M, Casasnovas C, García-Eroles L, Massons J, Balcells M. Clinical study of 39 patients with atypical lacunar syndrome. J Neurol Neurosurg Psychiatry. 2006;77(3):381-384.

12. Arsava EM, Bayrlee A, Vangel M, et al. Severity of leukoaraiosis determines clinical phenotype after brain infarction. Neurology. 2011;77(1): $55-61$.

13. Vermeer SE, Hollander M, van Dijk EJ, et al. Silent brain infarcts and white matter lesions increase stroke risk in the general population: the Rotterdam Scan Study. Stroke. 2003;34(5):1126-1129.

14. Sonohara K, Kozaki K, Akishita M, et al. White matter lesions as a feature of cognitive impairment, low vitality and other symptoms of geriatric syndrome in the elderly. Geriatr Gerontol Int. 2008;8(2):93-100.

15. Decarli C. Clinically asymptomatic vascular brain injury: a potent cause of cognitive impairment among older individuals. $J$ Alzheimers Dis. 2013;33(Suppl 1):S417-S426.

16. Conijn MM, Kloppenborg RP, Algra A, et al. Cerebral small vessel disease and risk of death, ischemic stroke, and cardiac complications in patients with atherosclerotic disease: the Second Manifestations of ARTerial disease-Magnetic Resonance (SMART-MR) study. Stroke. 2011;42(11):3105-3109.

17. Taub A. Acupuncture. Science. 1972;178(4056):9. 
18. Wang H, Xie Y, Zhang Q, et al. Transcutaneous electric acupoint stimulation reduces intra-operative remifentanil consumption and alleviates postoperative side-effects in patients undergoing sinusotomy: a prospective, randomized, placebo-controlled trial. Br J Anaesth. 2014;112(6):1075-1082.

19. Wang J, Wan Y. Acupuncture mechanisms: anesthesia, analgesia and protection on organ functions. World J Tradit Chin Med. 2015;1:59-66.

20. Kjeldsen HB, Klausen TW, Rosenberg J. Preferred presentation of the visual analog scale for measurement of postoperative pain. Pain Pract. 2016;16(8):980-984.

21. Ely EW, Inouye SK, Bernard GR, et al. Delirium in mechanically ventilated patients: validity and reliability of the confusion assessment method for the intensive care unit (CAM-ICU). JAMA. 2001;286(21):2703-2710.

22. Ely EW, Margolin R, Francis J, et al. Evaluation of delirium in critically ill patients: validation of the Confusion Assessment Method for the Intensive Care Unit (CAM-ICU). Crit Care Med. 2001;29(7):1370-1379.

23. Sessler CN, Gosnell MS, Grap MJ, et al. The Richmond AgitationSedation Scale: validity and reliability in adult intensive care unit patients. Am J Respir Crit Care Med. 2002;166(10):1338-1344.

24. Ely EW, Truman B, Shintani A, et al. Monitoring sedation status over time in ICU patients: reliability and validity of the Richmond AgitationSedation Scale (RASS). JAMA. 2003;289(22):2983-2991.

25. Weinstein SM, Poultsides L, Baaklini LR, et al. Postoperative delirium in total knee and hip arthroplasty patients: a study of perioperative modifiable risk factors. Br J Anaesth. 2018;120(5):999-1008.

26. Krenk L, Rasmussen LS, Kehlet H. New insights into the pathophysiology of postoperative cognitive dysfunction. Acta Anaesthesiol Scand. 2010;54(8):951-956.

27. Chapman SL, Byas-Smith MG, Reed BA. Effects of intermediate- and long-term use of opioids on cognition in patients with chronic pain. Clin J Pain. 2002;18(4 Suppl):S83-S90.

28. Whittington RA, Virág L, Marcouiller F, et al. Propofol directly increases tau phosphorylation. PLoS One. 2011;6(1):e16648.

29. Marcantonio ER. Postoperative delirium: a 76-year-old woman with delirium following surgery. JAMA. 2012;308(1):73-81.

30. Zhou J, Chi H, Cheng TO, et al. Acupuncture anesthesia for open heart surgery in contemporary China. Int J Cardiol. 2011;150(1):12-16.

31. Liu X, Wang J, Wang B, et al. Effect of transcutaneous acupoint electrical stimulation on propofol sedation: an electroencephalogram analysis of patients undergoing pituitary adenomas resection. BMC Complement Altern Med. 2016;16:33.

32. Yao Y, Zhao Q, Gong C, et al. Transcutaneous electrical acupoint stimulation improves the postoperative quality of recovery and analgesia after gynecological laparoscopic surgery: a randomized controlled trial. Evid Based Complement Alternat Med. 2015;2015:324360.

33. Blyth BJ, Farhavar A, Gee C, et al. Validation of serum markers for blood-brain barrier disruption in traumatic brain injury. J Neurotrauma. 2009;26(9):1497-1507.

34. Kanner AA, Marchi N, Fazio V, et al. Serum S100beta: a noninvasive marker of blood-brain barrier function and brain lesions. Cancer. 2003 97(11):2806-2813

35. Marchi N, Rasmussen P, Kapural M, et al. Peripheral markers of brain damage and blood-brain barrier dysfunction. Restor Neurol Neurosci. 2003;21(3-4):109-121.

36. Cata JP, Abdelmalak B, Farag E. Neurological biomarkers in the perioperative period. Br J Anaesth. 2011;107(6):844-858.

37. Vandooren J, van Damme J, Opdenakker G. On the structure and functions of gelatinase B/matrix metalloproteinase-9 in neuroinflammation. Prog Brain Res. 2014;214:193-206.

38. Rempe RG, Hartz AMS, Bauer B. Matrix metalloproteinases in the brain and blood-brain barrier: versatile breakers and makers. J Cereb Blood Flow Metab. 2016;36(9):1481-1507.

39. Ali MS, Harmer M, Vaughan R. Serum S100 protein as a marker of cerebral damage during cardiac surgery. Br J Anaesth. 2000;85(2):287-298.

40. Nguyen DN, Spapen H, Su F, et al. Elevated serum levels of S-100beta protein and neuron-specific enolase are associated with brain injury in patients with severe sepsis and septic shock. Crit Care Med. 2006;34(7) 1967-1974.
41. Shen X, Dong Y, Xu Z, et al. Selective anesthesia-induced neuroinflammation in developing mouse brain and cognitive impairment. Anesthesiology. 2013;118(3):502-515.

42. Tao G, Zhang J, Zhang L, et al. Sevoflurane induces tau phosphorylation and glycogen synthase kinase $3 \beta$ activation in young mice. Anesthesiology. 2014;121(3):510-527.

43. Zheng $\mathrm{H}$, Dong Y, Xu Z, et al. Sevoflurane anesthesia in pregnant mice induces neurotoxicity in fetal and offspring mice. Anesthesiology. 2013; 118(3):516-526.

44. Spiegel DR, Chen V. A case of postoperative cognitive decline, with a highly elevated C-reactive protein, status post left ventricular assist device insertion: a review of the neuroinflammatory hypothesis of delirium. Innov Clin Neurosci. 2012;9(1):35-41.

45. Bjornsson GL, Thorsteinsson L, Gudmundsson KO, Jonsson H, Gudmundsson S, Gudbjornsson B. Inflammatory cytokines in relation to adrenal response following total hip replacement. Scand J Immunol. 2007;65(1):99-105.

46. Kragsbjerg P, Holmberg H, Vikerfors T. Serum concentrations of interleukin-6, tumour necrosis factor-alpha, and C-reactive protein in patients undergoing major operations. Eur J Surg. 1995;161(1):17-22.

47. Alexander JJ, Jacob A, Cunningham P, Hensley L, Quigg RJ. TNF is a key mediator of septic encephalopathy acting through its receptor, TNF receptor-1. Neurochem Int. 2008;52(3):447-456.

48. Qu T, Uz T, Manev H. Inflammatory 5-LOX mRNA and protein are increased in brain of aging rats. Neurobiol Aging. 2000;21(5): $647-652$.

49. Thompson WL, Karpus WJ, van Eldik LJ. MCP-1-deficient mice show reduced neuroinflammatory responses and increased peripheral inflammatory responses to peripheral endotoxin insult. J Neuroinflammation. 2008;5:35

50. Bagnall N, Faiz OD. Delirium, frailty and IL-6 in the elderly surgical patient. Langenbecks Arch Surg. 2014;399(6):799-800.

51. Liu P, Li YW, Wang XS, et al. High serum interleukin-6 level is associated with increased risk of delirium in elderly patients after noncardiac surgery: a prospective cohort study. Chin Med J. 2013;126(19): 3621-3627.

52. Vasunilashorn SM, Ngo L, Inouye SK, et al. Cytokines and postoperative delirium in older patients undergoing major elective surgery. J Gerontol A Biol Sci Med Sci. 2015;70(10):1289-1295.

53. Benisty S, Gouw AA, Porcher R, et al. Location of lacunar infarcts correlates with cognition in a sample of non-disabled subjects with agerelated white-matter changes: the LADIS study. J Neurol Neurosurg Psychiatry. 2009;80(5):478-483.

54. Grau-Olivares M, Bartrés-Faz D, Arboix A, et al. Mild cognitive impairment after lacunar infarction: voxel-based morphometry and neuropsychological assessment. Cerebrovasc Dis. 2007;23(5-6): 353-361.

55. Gold G, Kövari E, Herrmann FR, et al. Cognitive consequences of thalamic, basal ganglia, and deep white matter lacunes in brain aging and dementia. Stroke. 2005;36(6):1184-1188.

56. Blanco-Rojas L, Arboix A, Canovas D, Grau-Olivares M, Oliva Morera JC, Parra O. Cognitive profile in patients with a first-ever lacunar infarct with and without silent lacunes: a comparative study. BMC Neurol. 2013;13:203.

57. Bickel H, Gradinger R, Kochs E, Förstl H. High risk of cognitive and functional decline after postoperative delirium. A three-year prospective study. Dement Geriatr Cogn Disord. 2008;26(1):26-31.

58. Lundström M, Edlund A, Bucht G, Karlsson S, Gustafson Y. Dementia after delirium in patients with femoral neck fractures. $J$ Am Geriatr Soc. 2003;51(7):1002-1006.

59. Witlox J, Eurelings LS, de Jonghe JF, Kalisvaart KJ, Eikelenboom P, van Gool WA. Delirium in elderly patients and the risk of postdischarge mortality, institutionalization, and dementia: a meta-analysis. JAMA. 2010;304(4):443-451.

60. Arboix A, García-Eroles L, Massons J, Oliveres M, Targa C. Lacunar infarcts in patients aged 85 years and older. Acta Neurol Scand. 2000; 101(1):25-29. 


\section{Publish your work in this journal}

Clinical Interventions in Aging is an international, peer-reviewed journal focusing on evidence-based reports on the value or lack thereof of treatments intended to prevent or delay the onset of maladaptive correlates of aging in human beings. This journal is indexed on PubMed Central, MedLine,

CAS, Scopus and the Elsevier Bibliographic databases. The manuscript management system is completely online and includes a very quick and fair peer-review system, which is all easy to use. Visit http://www.dovepress. com/testimonials.php to read real quotes from published authors. 